Indonesian Journal of Biotechnology, December, 2013

Vol. 18, No. 2, pp.116-122

\title{
Ethanol Fermentation on Mixed Sugars Using Mixed Culture of Two Yeast Strains
}

\author{
Jasman $^{1,2^{*}}$, Irfan Dwidya Prijambada ${ }^{3}$, Chusnul Hidayat $^{4}$, dan Donny Widianto ${ }^{3}$
}

${ }^{1}$ Biotechnology Study Program, Universitas Gadjah Mada

${ }^{2}$ Science Education Department, Universitas Nusa Cendana

${ }^{3}$ Faculty of Agriculture, Universitas Gadjah Mada

${ }^{4}$ Faculty of Agriculture Technology, Universitas Gadjah Mada

\begin{abstract}
The objective of this study was to evaluate the use of mixed cultures of the recommended yeast strains from a previous study on ethanol fermentation using a substrate mixture consisting of sucrose, glucose, and fructose. There were three mixed (combination) cultures namely OUT7096/OUT7913, OUT7096/OUT7921, and OUT7913/OUT7921. The fermentation medium contained sugar mixture consisting of glucose, fructose, and sucrose with a composition generally close to the composition of sugars in sweet sorghum juice. Overall, fermentation is carried out in two stages. First fermentation was performed using the three mixed cultures to determine the best combination based on the concentration of ethanol produced and the concentration of residual sugar. Second fermentation was conducted using the best mixed culture obtained from the first stage. This second stage was intended to describe the pattern of the changes in the concentration of ethanol, sugars and biomass during the fermentation progresses and to determine some kinetic parameters namely ethanol yield $\left(\mathrm{Y}_{\mathrm{p} / \mathrm{s}}\right)$, growth yield $\left(\mathrm{Y}_{\mathrm{x} / \mathrm{s}}\right)$ and specific growth rate $(\mu)$. The results of the first fermentation showed that the best mixed culture was OUT7913/OUT7921 and the subsequent fermentation using this culture provide the highest ethanol yield $\left(\mathrm{Y}_{\mathrm{p} / \mathrm{s}}\right)=0.47 \mathrm{~g} \cdot \mathrm{g}^{-1}$ that was reached at $53^{\text {rd }}$ hour, growth yield $\left(\mathrm{Y}_{\mathrm{x} / \mathrm{s}}\right)=0.425 \mathrm{~g} \cdot \mathrm{g}-1$, and $\mu=0.12$ hour $^{-1}$.
\end{abstract}

Keywords : fermentation, ethanol, mixed culture, mixed sugar

\section{Introduction}

Saccharomyces cerevisiae is widely used for the production of alcohol and ethanol fuel through a fermentation process that converting sugar into ethanol. This microbe can produce a lot of ethanol and has a high tolerance to ethanol and other growth inhibitors compounds (Balat et al., 2008). S. cerevisiae is able to produce $50 \mathrm{mmol}$ of ethanol per hour per gram of cell protein in optimum conditions (Dombek and Ingram, 1987). Conversion of sugar into ethanol by $S$. cerevisiae takes place in anaerobic condition through a series of biochemical

${ }^{*}$ Corresponding author:

Jasman

Biotechnology Study Program, Gadjah Mada University reactions called Embden Meyerhof Parnas pathway (EMP) or glycolysis which produces pyruvic acid. Furthermore, the pyruvic acid is converted to ethanol in two steps namely decarboxylation of pyruvic acid into acetaldehyde and then the reduction of the acetaldehyde to the ethanol (Lehninger et al., 2004).

The ethanol fermentation of substrates having a high concentration of sugar consisting of glucose, fructose, and sucrose could not fully proceed. This is because most of yeast is unable to convert sugar, especially fructose, completely during the fermentation (Wu et al., 2010). This problem occurs because the yeast prefers both sucrose and glucose to fructose. The fructose conversion takes place when the concentration of ethanol is already high enough to poison the yeast resulting 
in the low conversion of fructose ( $\mathrm{Wu}$ et al., 2010). To enhance the conversion of the substrate, it is required a culture of yeast, which is not only has a high ability to convert glucose and sucrose, but also to convert the other sugar components including fructose.

Sweet sorghum is a very potential crop for bioethanol production because of some advantages over the other crops (Reddy et al., 2006). Sugar content in sweet sorghum juice is mainly consisted of sucrose, glucose, and fructose. Composition of the sugars depend on the variety, planting time (Teetor et al., 2010), and harvest time (Almodares et al., 2007). Generally, concentration of sucrose is the highest among the sugars concentration, where as glucose and fructose almost have the same concentration. Therefore, in order to use the juice in ethanol production, it is required a culture being able to convert all of the sugars into ethanol completely.

A certain yeast strain will has different capabilities when used on substrates of different sugars. Meanwhile, some substrates containing the same type of sugar with the same concentration would result in a different amount of ethanol when fermented with different yeast strains. Different results will also be obtained when the used sugar is in a mixed form (Jasman et al., 2012). Therefore, medium consisting of several different sugars may be more suitable fermented by mixed culture.

According to Hesseltine (1992), a mixed culture has the advantages over a single one. For example:(1) The yield of fermentation could be higher; (2) The rate of cell growth could be higher if one organism produces growth factors or compounds essential to the growth of other organisms; (3) Compounds made by a mixture of microorganisms often complement each other and work to the exclusion of unwanted microorganisms; (4) Mixed cultures permit better utilization of the substrate; (5) Mixedculture fermentations enable the utilization of cheap and impure substrates.

The use of mixed culture in fermentation have been conducted in many cases but there has not been any report about using a mixed culture of two Saccharomyces strains in ethanol production from sugar mixture. Such cultures were used in this study to ethanol production from sugars mixture consisting of glucose, fructose, and sucrose with a composition generally close to that of sweet sorghum juice. This was performed to evaluate the capability of the cultures previous to applying it in ethanol production from sweet sorghum juice.

\section{Materials and Method Yeast}

There are three recommended strains of yeasts from our previous study namely OUT7096, OUT7913, and OUT7921. The three strains of yeast were obtained from Prof. Satoshi Harashima, Dept. of Biotechnology, Fac. of Engineering, Osaka University, Japan. All yeast isolates were maintained on Malt Extract Agar (MEA) at $4^{\circ} \mathrm{C}$ in the refrigerator and were sub-cultured every 2 months.

\section{Fermentation Media}

Fermentation media were consisting of glucose, fructose, sucrose, yeast extract, peptone, $\mathrm{MgSO}_{4} 7 \mathrm{H}_{2} \mathrm{O}$, and $\mathrm{K}_{2} \mathrm{HPO}_{4}$ Sucrose was obtained from Difco; yeast extract and peptone from Himedia, while others were purchased from Merck. Fermentation media were prepared by mixing the materials with the composition of $2.5 \%$ glucose, $2.5 \%$ fructose, $5.0 \%$ sucrose, $0.5 \%$ yeast extract, $0.5 \%$ peptone, $0.15 \% \mathrm{MgSO}_{4} 7 \mathrm{H}_{2} \mathrm{O}$, and 0.15 $\% \mathrm{~K}_{2} \mathrm{HPO}_{4}$.

\section{Inoculum Preparation}

Inocula were prepared by culturing each strain in a medium containing 2.5 $\%$ glucose, $2.5 \%$ fructose, $5.0 \%$ sucrose, $0.15 \% \mathrm{MgSO}_{4} 7 \mathrm{H}_{2} \mathrm{O}, 0.15 \% \mathrm{~K}_{2} \mathrm{HPO}_{4}, 0.5 \%$ yeast extract, and $0.5 \%$ peptone in $250 \mathrm{ml}$ Erlenmeyer flask with a working volume of $100 \mathrm{ml}$. Incubation was carried out on an orbital shaker at $100 \mathrm{rpm}$ and temperature of $30^{\circ} \mathrm{C}$, for 12 to 24 hours or until the cell density reached $10^{8}$ cells $\mathrm{ml}^{-1}$. 


\section{Ethanol Fermentation}

Ethanol fermentation was performed in two steps. The first step was to elucidate the best strains combination in producing ethanol and the second was to describe the pattern of the changes in the concentration of ethanol, sugars and biomass during the fermentation progress. The first step was carried out using mixed cultures consisting of OUT7096/OUT7921, OUT7913/7921, and OUT7913/OUT7096. The second step was conducted using only the best cultures obtained from the first step.

The first step was started by mixing two selected inocula with ratios of 1:3, 1:1, and $3: 1$ into three of a one liter sterilized fermentation jars respectively and then 800 $\mathrm{ml}$ medium was added aseptically. The initial concentration of each strain is $7 \times 10^{7}$ cell $\mathrm{ml}^{-1}$. Incubation was carried out at $30^{\circ} \mathrm{C}$ for 72 hours. The residual sugar and ethanol content were analyzed. The experiment was performed triplicates.

The second step was performed using only the best mixed culture obtained from the first step. During the incubation period, samples were collected every 4 hours and directly stored in a freezer for analysis of sugars and ethanol.

Ethanol yield $\left(Y_{p / s}\right)$ is obtained by comparing the ethanol concentration to the concentration of sugars consumed during exponential phase. Mathematically, ethanol yield is calculated using:

$Y p / s=\frac{p-p o}{S o-S}$

$\mathrm{P}$ = final ethanol concentration;

$\mathrm{P}_{0}=$ initial ethanol concentration

$S$ = final substrate (sugars) concentration;

$\mathrm{S}_{0}=$ initial substrate concentration

(Riadi, 2007)

Efficiency of sugar conversion to ethanol which expressing the ability of yeast to convert the available sugar into ethanol was calculated by equation:
$S C E=\frac{\text { alcohol content }\left(\% \frac{W}{V}\right) \times 100}{\text { media sugar content }(\%) \times 0.504}$

$S C E=$ sugar conversion efficiency

(de Mancilha et al., 1984a)

Growth yield of biomass during fermentation progress was calculated using equation:

$Y x / s=\frac{x-x O}{s O-s}$

$X_{0}$ and $X=$ initial and final concentration of dried weight of biomass respectively;

$S_{0}$ and $S=$ initial and final concentration of substrate respectively.

(Stanbury et al., 1995).

Analysis of sugars and ethanol was performed using an HPLC system (Knauer smartline RI detector 2300, Germany) using a column of Aminex HPX-87C $300 \times 7.8 \mathrm{~mm}$ (Bio-Rad, USA) at $85^{\circ} \mathrm{C}$. Injection volume is $20 \mu \mathrm{L}$ and mobile phase is deionized water at flow rate of $0.6 \mathrm{ml} \mathrm{min}^{-1}$.

\section{Result and discussion}

Determination of the best mixed cultures for sugar mixture fermentation

The results of first fermentation can be seen in Table 1. The table shows that both the highest ethanol concentration and the highest yield were produced by strain combination of OUT7921/OUT7913 and OUT7921/ OUT7096 at ratio of 1:1. Single culture of strain OUT7906 as control also provided both a high ethanol concentration and yield but it was still lower than those produced by the both mixed culture of OUT7921/ OUT7913 and OUT7921/OUT7096. The combination of OUT7913/OUT7096 was the only combination that produced lower both concentration and yield of ethanol compared with the controls. The excellence of OUT7921/OUT7913 mixed culture was in accordance with the results of our previous studies which showed that the OUT7921 strain excellence in the fermentation of 
Table 1. Concentrations of ethanol and sugars after fermentation and ethanol yield

\begin{tabular}{|c|c|c|c|c|c|c|c|c|}
\hline $\begin{array}{c}\text { Strain } \\
\text { Combination }\end{array}$ & $\begin{array}{c}\text { strain } \\
\text { ratio }\end{array}$ & $\begin{array}{l}\text { ethanol } \\
(\% \mathrm{v} / \mathrm{v})\end{array}$ & $\begin{array}{l}\text { glucose } \\
(\% \mathrm{w} / \mathrm{v})\end{array}$ & $\begin{array}{l}\text { fructose } \\
(\% \mathrm{w} / \mathrm{v})\end{array}$ & $\begin{array}{l}\text { sucrose } \\
(\% \mathrm{w} / \mathrm{v})\end{array}$ & $\begin{array}{c}\text { sugar (\% } \\
\mathrm{w} / \mathrm{v}) \\
\end{array}$ & $\begin{array}{c}\text { consumed } \\
\text { sugar }(\% \mathrm{w} / \mathrm{v})\end{array}$ & $\begin{array}{c}\mathrm{Yp} / \mathrm{s} \\
\left(\mathrm{ml} \cdot \mathrm{g}^{-1}\right)\end{array}$ \\
\hline OUT7921 & $1: 3$ & 4.59 & 0.04 & 0.10 & 0.33 & 0.47 & 9.53 & 0.48 \\
\hline+ & $1: 1$ & 6.22 & 0.09 & 0.14 & 0.08 & 0.31 & 9.69 & 0.64 \\
\hline OUT7096 & $3: 1$ & 4.11 & 0.02 & 0.08 & 0.18 & 0.28 & 9.72 & 0.42 \\
\hline OUT7921 & $1: 3$ & 4.49 & 0.04 & 0.08 & 0.44 & 0.56 & 9.44 & 0.48 \\
\hline+ & $1: 1$ & 6.36 & 0.00 & 0.06 & 0.15 & 0.21 & 9.79 & 0.65 \\
\hline OUT7913 & $3: 1$ & 3.88 & 0.02 & 0.10 & 0.25 & 0.36 & 9.64 & 0.40 \\
\hline OUT7913 & $1: 3$ & 3.06 & 0.06 & 0.11 & 0.01 & 0.18 & 9.83 & 0.31 \\
\hline+ & $1: 1$ & 5.58 & 0.01 & 0.10 & 0.02 & 0.13 & 9.87 & 0.57 \\
\hline OUT7096 & $3: 1$ & 2.98 & 0.03 & 0.03 & 0.01 & 0.07 & 9.93 & 0.30 \\
\hline \multicolumn{9}{|c|}{ Control } \\
\hline \multicolumn{2}{|c|}{ OUT7921 } & 5.97 & 0.01 & 0.09 & 0.26 & 0.36 & 9.64 & 0.62 \\
\hline \multicolumn{2}{|c|}{ OUT7913 } & 5.63 & 0.01 & 0.07 & 0.08 & 0.15 & 9.85 & 0.57 \\
\hline \multicolumn{2}{|c|}{ OUT7096 } & 6.09 & 0.00 & 0.12 & 0.33 & 0.45 & 9.55 & 0.64 \\
\hline
\end{tabular}

sucrose and glucose-fructose mixture into ethanol, while the OUT7913 strain excellence in the fermentation of a mixture of glucosefructose-sucrose (Jasman et al., 2012).

The mixed culture of OUT7913/ OUT7096 at ratio of 3:1 used most of sugar but it produced the least amount of ethanol. This result suggested that the combination of these two strains at this ratio was less efficient in converting sugar into ethanol compared with other cultures. This case may be caused by domination of one strain to another, so that, they could not work cooperatively. From Table 1, it can also be observed that the mixed culture which produced the highest concentration of ethanol was at ratio of 1:1. This may indicate that the two strains can work cooperatively and do not dominate each other. Effect of cell number ratio in the inoculum has been reported by Lee et al. (2013) in fermentation of papaya wine using $W$. saturnus and S. cerevisiae.

It can also be seen that the concentrations of glucose and sucrose residues after fermentation were almost always less than the concentration of fructose. It is suggested that the yeast prefers to consume glucose than fructose. This result is in accordance with the results of previous studies (Jasman et al., 2012, Tronchoni et al., 2009; and Berthels et al., 2004).
Guillaume et al. (2007) assumed that differences in glucose and fructose consumption are due to the differences in transporting both compounds across cell plasma membranes. Analyses of the effect of HXT gene inactivation have shown that the hexose carriers Hxt1 to Hxt7 are the main transporters. These carriers classified into low-, intermediate-, and high-affinity transporters. Both high- and low-affinity transporters have a higher affinity for glucose than for fructose (Reifenberger et al., 1997). Berthels et al (2008) conclude that the glucosefructose discrepancy in wine yeast strains correlates with the kinetic properties of hexokinase-mediated sugar phosphorylation.

\section{Fermentation of sugar mixture with mixed culture of OUT7913/OU77921}

Changes of sugars concentrations during the fermentation can be seen in Figure 1.Sucrose concentration decreased faster than the concentration of two other types of sugar. This is because the yeast producing invertase splitting sucrose molecules into glucose and fructose molecules. This membranebound enzyme breaks down sucrose into its hexose components during active transport of sucrose directly into the cell. This is an another uptake mechanism present in ethanolic yeasts (Rolz and de Leon, 2011). 
Figure 1 shows that the decrease in glucose concentration was faster than that of fructose during the $\log$ phase. The decline of sucrose, glucose, or fructose is in line with the exponential increase of ethanol concentration. The results also agreed with the previous research which showed that common ethanol fermentation yeasts, strain of $S$. Cerevisiae consume sugar in mixtures of fermentable sugar in the order of sucrose, glucose, and fructose (Berthels et al., 2004; Meneses et al., 2002).

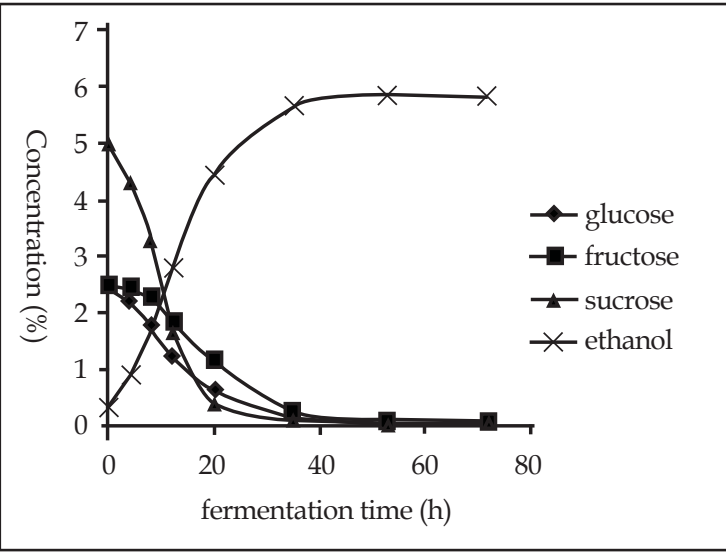

Figure 1. The changes of sugar and ethanol concentrations during fermentation at $30^{\circ} \mathrm{C}$ and initial pH 5,0.

Change in the concentration of ethanol during the fermentation was also shown in Figure 1. Ethanol concentration increase slowly until the $4^{\text {th }} \mathrm{h}$ and then it increase exponentially from the $4^{\text {th }} \mathrm{h}$ to $20^{\text {th }} \mathrm{h}$. Further increase in the concentration of ethanol starts to slow down until it reaches a maximum, that was $5.86 \% \mathrm{v} / \mathrm{v}$ equal to $4.62 \% \mathrm{w} / \mathrm{v}$, after another $37 \mathrm{~h}$. Calculating the ethanol yield using equation (1) give $Y_{p / s}=0.47 \mathrm{~g} \cdot \mathrm{g}^{-1}$.

Using the equation (2), we obtained SCE $=93.25$ which means that about $93.25 \%$ of substrate (sugars) can be converted to ethanol during the fermentation. This achievement is close to the value of $93.57 \%$ achieved by de Mancilha et al. $\left(1984^{\mathrm{b}}\right)$ who used S. cerevisiae IZ 1716 mut. on substrate of sweet sorghum juice.

The growth of yeast cells (biomass) during the fermentation can be seen on Figure 2.:

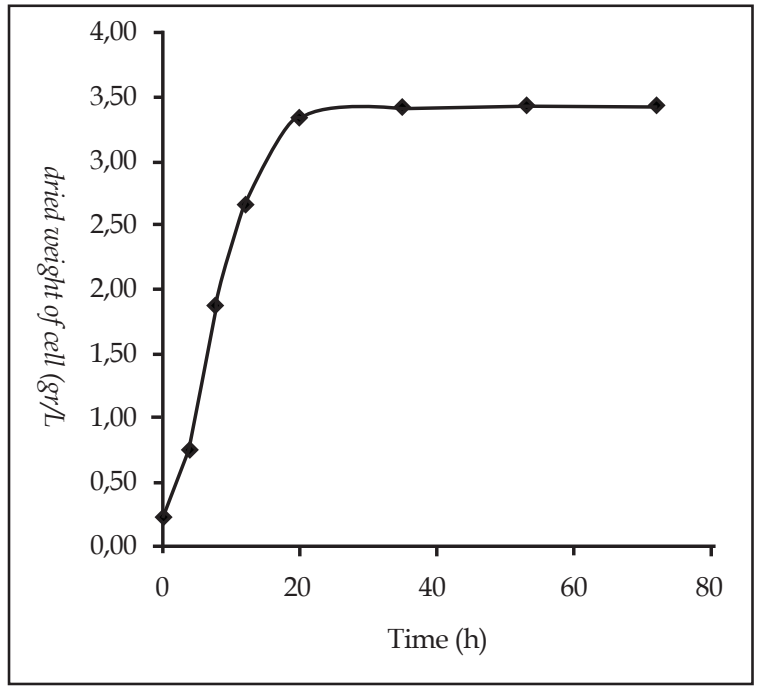

Figure 2. Biomass growth of yeast cells during fermentation of sugar mixtures at $30^{\circ} \mathrm{C}$ and initial pH 5.0

From the calculation, it was obtained $\mathrm{Y}_{\mathrm{x} / \mathrm{s}}=0.04 \mathrm{~g} \cdot \mathrm{g}^{-1}$ and $\mu=0.12 \mathrm{~h}^{-1}$. This value of specific growth was close to that of achieved by Pramanik et al. (2005) who used sucrose and a strain of $S$. cerevisiae isolated from toddy. These results indicated that mixed culture of yeast could work properly on substrate consisting of mixed sugars as well as single culture on substrate of single sugar.

In this study, the mixed culture at ratio of 1:1 can provide a satisfying result of fermentation on substrate consisting of sucrose, glucose, and fructose. Thus, the mixed culture is good for using in fermentation of natural substrates having sugar composition similar to those of used in this study such as sweet sorghum juice.

\section{Acknowledgements}

We would like to thank profusely to the Directorate General of Higher Education Republic's of Indonesia that has funded this research through the National Strategic Research Grants' scheme by contract number: 001/SP2H/PL/Dit.Litabmas/III/2011, Date Marc $7^{\text {th }}$ 2012. We also grateful Prof. Satoshi Harashima and Yoshinobu Kaneko of Osaka University, for providing us yeast strains. 


\section{Reference}

Almodares, A., M.R. Hadi, M. Ranjbar, R. Taheri, 2007. The effects of nitrogen treatment, cultivars and harvest stages on stalk yield and sugar content in sweet sorghum, As. J. Plant Sci., 6, 423-426.

Balat, M., H. Balat, and C. Öz, 2008. Progress in bioethanol processing, J. Prog. Ener. and Combust. Sci., 34, 551-573.

Berthels N.J., R.R.C. Otero, F.F. Bauer, J.M. Thevelein, and I.S. Proterius, 2004. Discrepancy in glucose and fructose utilization during fermentation by Saccharomyces cerevisiae wine yeast, FEMS Yeast Res., 4, 683-689.

Berthels N.J., R.R.C. Otero, F.F. Bauer, I.S. Proterius, 2008. Correlation between glucose/fructose discrepancy and hexokinase kinetic properties in different Saccharomyces cerevisiae wine yeast strains, Appl. Microbiol. Biotechnol., 77, 1083-1091.

de Mancilha, I. M., A. M. Pearson, J. Waller, and G. J. Hogaboam., 1984a . Technical Note: Increasing alcohol yield by selected yeast fermentation of sweet sorghum. I. Evaluation of yeast strains for ethanol production. Biotechnol. Bioeng., 26, 632634.

de Mancilha, I. M., A. M. Pearson, H. Momose, and J. J. Pestka., 1984 ${ }^{\text {b. Technical Note: }}$ Increasing alcohol yield by selected yeast fermentation of sweet sorghum. II. Isolation and evaluation of mutants and wild types for ethanol production. Food Chem., 14, 313-318.

Dombek, K.M. and L.O. Ingram, 1987. Ethanol production during batch fermentation with saccharomyces cerevisiae: Changes in glycolytic enzymes and internal $\mathrm{pH}$, Appl. and Env. Microbiol., 53, 1286-1291.

Guillaume, C., P. Delobel, J.M. Sablayrolles, B. Blondin., 2007. Molecular Basis of Fructose Utilization by the Wine Yeast Saccharomyces cerevisiae: a Mutated HXT3 Allele Enhances Fructose Fermentation, Appl. and Env. Microbiol., 73, 2432-2439.
Hesseltine, C. W., 1992. Mixed-Culture Fermentation, in Applications of Biotechnology to Traditional Fermented Foods, Washington DC: National Academy Press.

Jasman, I. D. Prijambada, C. Hidayat, and D. Widianto, 2012. Selection of yeast strains for ethanol fermentation of glucosefructose-sucrose mixture. Indonesian Jour. of Biotechnol., 2, 114-120.

Lee, P.R., S.H.C. Kho, Yu, B., P. Curran, and S.Q. Liu, 2013. Yeast ratio is a critical factor for sequential fermentation of papaya wine by Williopsis saturnus and Saccharomyces cerevisiae, Microbial Biotechnol., 6, 385-393.

Lehninger, A.L., D.L. Nelson, and M.M. Cox. (2004) Principles of Biochemistry, fourth edition, New York: W. H. Freeman \& Co.

Meneses, F.J., P.A. Henschke, and V. Jiranek., 2002. A survey of industrial strains of Saccharomyces cerevisiae revealas numerous altered patterns of maltose and sucrose utilization. J. Inst. Brew. 108, 310-321.

Pramanik, K. and D. E. Rao, 2005. Kinetic study on ethanol fermentation of grape waste using Saccharomyces cerevisiae yeast isolated from toddy. IE (I) JournalCH: 53-58.

Reddy, B.V.S, S. Ramesh, P.S. Reddy, A.A. Kumar, K.K. Sharma, S.M.K. Chetty, and A.R. Palaniswamy, 2006. Sweet Sorghum: Food, Feed, Fodder and Fuel Crop, India: ICRISAT.

Reifenberger, E., E. Boles, and M. Ciriacy, 1997. Kinetic characterization of individual hexose transporters of Saccharomyces cerevisiae and their relation to the triggering mechanisms of glucose repression Eur. J. Biochem., 245, 324-333.

Riadi, L., 2007. Teknologi Fermentasi, Yogyakarta: Graha Ilmu.

Rolz, C. and R. de Leon, 2011. Ethanol fermentation from sugarcane at different maturities, Inst. Crops and Prod., 33, 333337. 
Stanbury, P.F, A. Whitaker, S.J. Hall, 1995. Principles of Fermentation Technology (second edition). ButterworthHeinemann.

Teetor, V. H., V.D. Denise, T.W. Elisabeth, M.Y. Kelly, C. Jeerawan, K. R. Mark, T.R. Dennis, 2011. Effects of planting date on sugar and ethanol yield of sweet sorghum grown in Arizona, Ind. Crops and Prod. 34, 1293-1300.

Tronchoni J., A. Gamero, F.N. Arroyo-Lopez, E. Barrio, A. Querol, 2009. Differences in the Glucoses and fructose Consumption Profiles in Diverse Saccharomyces Wine Species and Their Hybrids During Grapes Juice Fermentation, Intl Jour. of Food Microbiol.,134, 237-243.

$\mathrm{Wu}$, X., S. Staggenborg, J.L. Propheter, W.L. Rooney, J. Yu, and D. Wang, 2010. Feature of sweet sorghum juice and their performance in ethanol fermentation, Ind. Crops and Prod., 31, 164-170. 